\title{
Two Cases of Acute Abdominal Intestinal Endometriosis
}

\author{
Murat Özgür Klıı̧', Serdar Gökay Terzioğlu', Duriye Özer Türkay², Servet Güreşçi2, Barış Saylam \\ 'Department of General Surgery, Ankara Numune Training and Research Hospital, Ankara, Turkey \\ 2Department of Pathology, Ankara Numune Training and Research Hospital, Ankara, Turkey
}

Cite this article as: Kılıç MÖ, Terzioğlu SG, Özer Türkay D, Güreşçi S, Saylam B. Two Cases of Acute Abdominal Intestinal Endometriosis. J Emerg Med Case Rep 2017; 8: 46-8.

\section{ABSTRACT}

Introduction: Gastrointestinal endometriosis is an uncommon form of extragenital endometriosis. The ileum and appendix are the most affected sites following the rectosigmoid region.

Case Report: Clinicopathological findings, diagnostic approaches, and therapeutic outcomes of two intestinal endometriosis patients who presented with acute abdomen findings were reviewed.

Conclusion: Although intestinal endometriosis is often difficult to diagnose using imaging methods, cyclic symptomatology and a history of obstetric/gynecologic surgery should alert clinicians to consider this diagnosis. Surgery seems to be the best treatment option and mainly depends on the affected site and clinical presentation.

Keywords: Acute appendicitis, acute bowel obstruction, intestinal endometriosis

Received: 03.08.2016 Accepted: 04.10.2016 Available Online Date: 30.11.2016

\section{Introduction}

Endometriosis is a common gynecologic disease, with an estimated incidence of approximately $15 \%$ of all women of reproductive age (1). It is characterized by the presence of endometrial glands and stroma outside the uterine cavity and is usually found in the ovaries, rectovaginal pouch, and pelvic peritoneum. However, extrapelvic sites such as the lungs, urinary tract, and gastrointestinal system are less affected sites (2). The rectosigmoid junction, ileum, and appendix are the most commonly reported regions for intestinal endometriosis (IE) (3). Although IE is usually asymptomatic, it may be presented with acute abdomen findings. Here we present the cases of two IE patients who underwent emergency surgeries.

\section{Case Reports}

Case 1: A 65-year-old woman presented with abdominal pain and nausea for $24 \mathrm{~h}$. She had a history of multiple cesarean sections and hysterectomy. On examination, defense and rebound tenderness were observed at the right lower quadrant of the abdomen. Inflammatory markers including white blood count (WBC) $(15.5 \mathrm{~K} / \mu \mathrm{L})$ and c-reactive protein (CRP) $(98.4 \mathrm{mg} / \mathrm{L})$ were elevated. On ultrasonography (US), enlarged appendix with a small amount of fluid between the intestines was detected.

During surgery, a hyperemic and enlarged appendix caused by a brownish mass in the middle part of the organ was found; therefore, a standard appendectomy was performed. The lesion was histopathologically diagnosed as appendicial endometriosis. The patient was discharged without any complication on the second postoperative day. No recurrence was observed during the follow-up period of 30 months.

Case 2: A 35-year-old woman presented with abdominal pain, nausea, vomiting, and obstipation for 3 days. She had a history of cesarean section. Her menstruation was quite painful for the previous 2 years. She also suffered from crampy abdominal pain, especially during the menstrual cycle. On examination, the abdomen was distended, bowel sounds were increased, and rectum was empty. Laboratory

Address for Correspondence:

Murat Özgür Kilıç, Department of General Surgery, Ankara Numune Training and Research Hospital, Ankara, Turkey

E-mail: murat05ozgur@hotmail.com

oCopyright 2017 by Emergency Physicians Association of Turkey - Available online at www.jemcr.org 


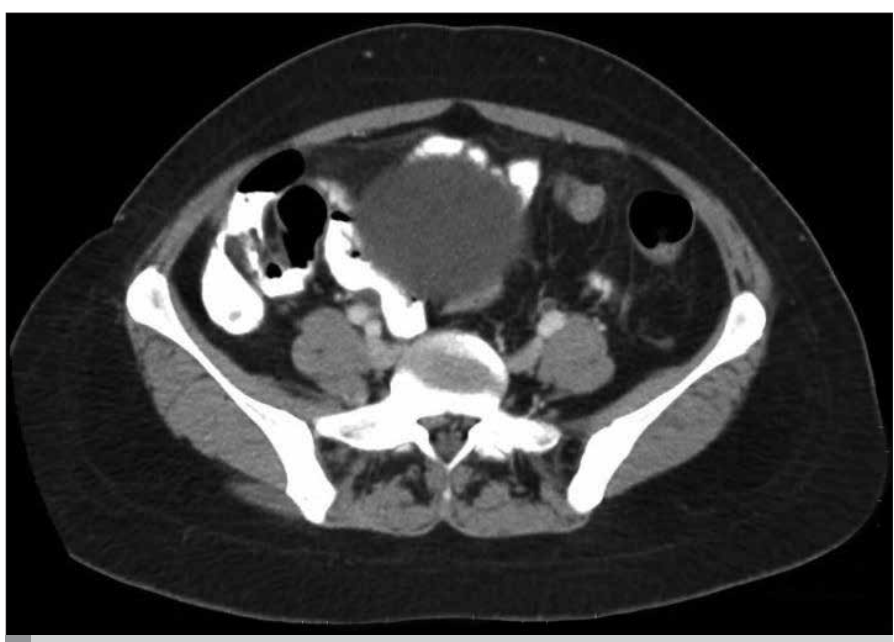

FIGURE 1. Tomographic view of dilated small intestines up to the ileocecal region

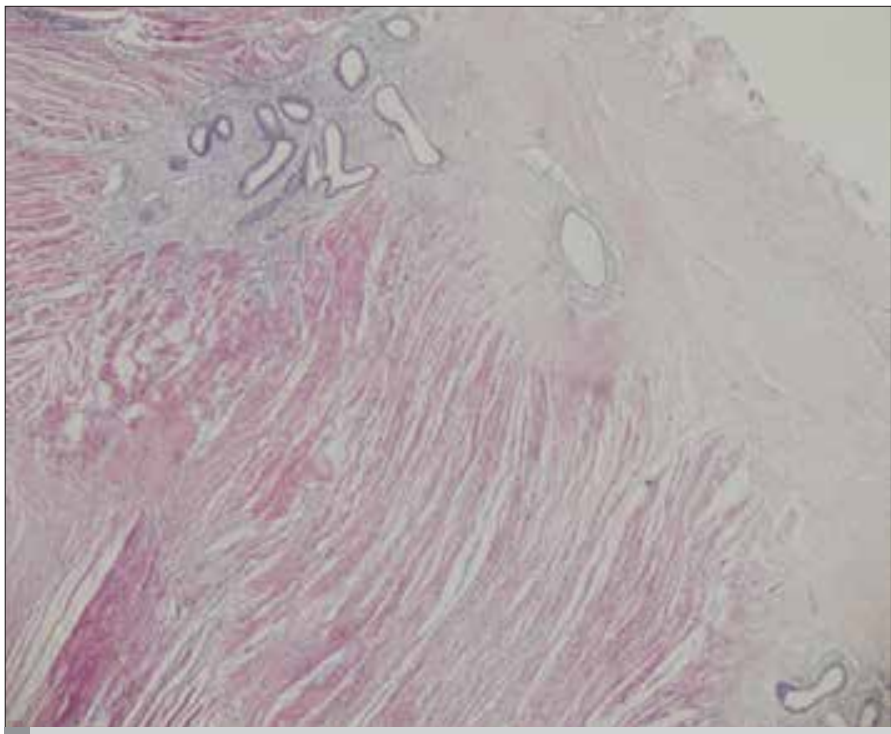

FIGURE 2. Histopathological appearance of endometrial glands and stromal tissue within the muscularis propria of colonic wall $(\mathrm{HE} \times 20)$

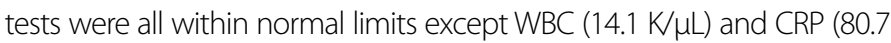
$\mathrm{mg} / \mathrm{L}$ ). Multiple air fluid levels were detected on abdominal radiography. Computed tomography (CT) showed a dilated small intestine up to the ileocecal region without any well-defined mass (Figure 1).

A right hemicolectomy was performed for the ileocecal mass, which led to the narrowing of the lumen and subsequent obstruction. Histopathologically, the mass was diagnosed as endometriosis (Figure 2). The patient was uneventfully discharged 1 week after the surgery. She is being followed up for 2 years with no further complaints.

Informed consent was obtained from both patients.

\section{Discussion}

Intestinal endometriosis has usually been reported as single case or small case series (4-6). Although its exact pathogenesis is unclear, ret- rograde spread of endometrial cells into the peritoneal cavity during menstruation and iatrogenic implantation of endometrial tissue during obstetric and gynecological surgeries are the most accepted theories. Similarly, both patients had a history of gynecological surgery. Most patients with IE are asymptomatic; however, clinical findings mainly depend on the affected site. Chronic abdominal and/or pelvic pain, nausea, vomiting, constipation, and diarrhea are the most frequent findings in symptomatic women. On the other hand, a small number of patients rarely present with various complicated conditions, such as intestinal perforation and obstruction, gastrointestinal or intraperitoneal bleeding, and acute appendicitis.

Intestinal endometriosis is an extremely rare cause of acute appendicitis, with only few reported cases in the literature (7). Although this uncommon condition is often seen in young adults, our patient was a 65-year-old woman. Acute bowel obstruction is the other rare clinical presentation of IE. Most women with IE are asymptomatic or have mild intestinal symptoms. Therefore, a surgical intervention is usually not indicated unless there is an associated infertility or acute bowel obstruction.

Unfortunately, diagnostic tools including US, CT, and magnetic resonance imaging have a limited diagnostic value before surgery, and hence, the majority of cases with IE can be diagnosed at surgery or final histopathological examination. Similarly, CT did not demonstrate an ileal mass and only showed the narrowing of the lumen and dilated intestines in our patient. Nevertheless, these imaging methods should be a routine part of the diagnostic work-up of patients with suspected IE because of the accompanying pelvic endometriosis, which is of great importance for surgical planning.

There are two main therapeutic options for IE, including medical treatment and surgery. Nonsteroidal anti-inflammatory drugs, $\mathrm{GnRH}$ analogs, and oral contraceptives are generally used in the treatment of symptomatic patients, with high recurrence rates (5). Surgery is generally indicated for patients who did not benefit from the medical treatment or developed recurrent lesion as well as those who presented with a serious complication. Recurrence rate is low after total excision of the lesion (8). Similarly, no recurrence was observed during the follow-up period of our patients.

\section{Conclusion}

Intestinal endometriosis is often difficult to diagnose using imaging methods. The presence of cyclic symptomatology and a history of obstetric/gynecologic surgery should alert the physicians to consider this diagnosis. Surgery seems to be the best treatment option and mainly depends on the affected site and clinical presentation.

Informed Consent: Written informed consent was obtained from patients who participated in this study.

Peer-review: Externally peer-reviewed.

Author contributions: Concept - M.Ö.K., B.S.; Design - M.Ö.K., S.G.T.; Supervision - M.Ö.K., B.S.; Resource - M.Ö.K., S.G.T.; Materials - M.Ö.K., S.G.T.; Data Collection and/or Processing - S.G.T., D.Ö.T., S.G.; Analysis and/or Interpretation - M.Ö.K.; Literature Search - M.Ö.K., S.G.T.; Writing - M.Ö.K.; Critical Reviews - M.Ö.K., B.S. 
Conflict of Interest: No conflict of interest was declared by the authors.

Financial Disclosure: The authors declared that this study has received no financial support.

\section{References}

1. Wolthuis AM, Meuleman C, Tomassetti C, D'Hooghe T, de Buck van Overstraeten A, D'Hoore A. Bowel endometriosis: colorectal surgeon's perspective in a multidisciplinary surgical team. World J Gastroenterol 2014; 20: 15616-23. [CrossRef]

2. Horton JD, Dezee KJ, Ahnfeldt EP, Wagner M. Abdominal wall endometriosis: a surgeon's perspective and review of 445 cases. Am J Surg 2008; 196: 207-12. [CrossRef]

3. Remorgida V, Ferrero S, Fulcheri E, Ragni N, Martin DC. Bowel endometriosis: presentation, diagnosis and treatment. Obstet Gynecol Surv 2007; 62: 461-70. [CrossRef]
4. Ito D, Kaneko S, Morita K, Seiichiro S, Teruya M, Kaminishi M. Cecal volvulus caused by endometriosis in a young woman. BMC Surg 2015; 15: 77. [CrossRef]

5. Acar T, Acar N, Çelik SC, Ekinci N, Tarcan E, Çapkınoğlu E. Endometriosis within the sigmoid colon/extragenital endometriosis. Ulus Cerrahi Derg 2015; 31: 250-2. [CrossRef]

6. Kim JS, Hur H, Min BS, Kim H, Sohn SK, Cho CH, et al. Intestinal endometriosis mimicking carcinoma of rectum and sigmoid colon: a report of five cases. Yonsei Med J 2009; 50: 732-5. [CrossRef]

7. Emre A, Akbulut S, Yilmaz M, Bozdag Z. An unusual cause of acute appendicitis: Appendiceal endometriosis. Int J Surg Case Rep 2013; 4: 547. [CrossRef]

8. Meuleman C, Tomassetti C, D'Hoore A, Van Cleynenbreugel B, Penninckx F, Vergote I, et al. Surgical treatment of deeply infiltrating endometriosis with colorectal involvement. Hum Reprod Update 2011; 17: 311-26.[CrossRef] 